NOTICE: This is the author's version of a work that was accepted for publication in Legal Medicine. Changes resulting from the publishing process, such as peer review, editing, corrections, structural formatting, and other quality control mechanisms, may not be reflected in this document. Changes may have been made to this work since it was submitted for publication. A definitive version was subsequently published in Legal Medicine, VOLUME 16, (2014) 20-25

\title{
Analysis of Y chromosome haplogroups in Japanese population using short amplicons and its application in forensic analysis
}

Yuta Harayama, Sayako Kamei, Noriko Sato, Tokutaro Hayashi, Tetsuya Shiozaki, Masao Ota, Hideki Asamura

Abstract

We designed three mini multiplex PCR systems using single-base extension reactions to identify Japanese Y chromosome haplogroups. We selected a group of $22 \mathrm{Y}$ chromosome single nucleotide polymorphisms (SNPs) from the haplogroups most commonly reported in East Asia. To make the systems more useful in analyzing degraded DNA samples, we designed primers to render amplicons of $\leq 150 \mathrm{bp}$. Applying these systems, we classified the Japanese population into major haplogroups and confirmed the applicability of these systems in forensic DNA analysis.

Keywords:

Y chromosome SNPs; Multiplex single base extension reactions; Degraded DNA; Short PCR products

1. Introduction

Short tandem repeat (STR) markers are highly effective in determining personal identity, and Y chromosome STR loci and population genetic data from a wide range of ethnic groups are now routinely used in forensics [1-4]. While SNPs have also been applied in kinship testing, more of these binary markers than STRs are required to be useful. However, SNPs have certain advantages over STRs, including much greater mutational stability and good performance when typing highly degraded DNA [5-7]. The Y chromosome carries the largest amount of non-recombining DNA and contains stable binary markers that can be used in evolutionary studies. Y chromosome SNPs typing can help trace the origins and history of human populations by tracking migrational patterns [8].

The human Y chromosome tree contains 20 major clades, consisting of 311 distinct haplogroups defined by hundreds of binary markers $[9,10]$. To classify the Japanese population, we selected haplogroups C, D, and $\mathrm{O}$, reported as major haplogroups in Japan and East Asia, and haplogroups $\mathrm{N}$ and $\mathrm{Q}$, found at low frequencies in Japan $[9,11]$. Recent reports indicate that much of the Japanese population can be subdivided into sub-haplogroups D2 and O2 [9]. We established three mini multiplex PCR systems to classify the Japanese population. System 1 is capable of classifying the Japanese population into the major clades C, D, D1, D2, D3, O, O1a, O2, O3, N, and Q. System 2 subdivides clade D2; System 3 subdivides clade $\mathrm{O} 2$. These PCR systems use single-base extension (SBE) reactions.

The goal of this study was to develop methods for analyzing difficult DNA samples encountered in 
forensics. The analysis of highly fragmented DNA or samples containing PCR inhibitors using commercially-available STR typing kits often fails to resolve informative profiles. Several methods have been proposed to remove the inhibitors or reduce their effects. MiniSTR analysis allows us to analyze degraded DNA samples efficiently by obtaining short PCR products [12-16]. We focused on Y chromosome SNPs used in haplogroup classification and applied the present systems to personal identification tasks. The advantage of using the simultaneously detected multiplex system of $\mathrm{Y}$ chromosome SNPs is the capacity to predict the haplogroup even if the typing of the alleles is incomplete. To make the systems more useful with such samples, we designed primers to render amplicons of $\leq 150 \mathrm{bp}$. We analyzed highly degraded DNA to determine the efficacy of these multiplex systems.

2. Materials and methods

\subsection{Samples and DNA extraction}

This study was approved by the Ethics Committee of Shinshu University. After obtaining informed consent, we collected samples from 432 healthy unrelated adult Japanese males representing virtually every prefecture in Japan (including Hokkaido and Okinawa) and extracted DNA from blood or buccal mucosa cells using the QIAamp DNA Blood Mini Kit (Qiagen, Hilden, Germany). We also extracted DNA from various male bone samples by SDS-proteinase $\mathrm{K}$ treatment followed by phenol/chloroform extraction.

\subsection{Primer design and multiplex PCR amplification}

We selected 22 SNPs from the non-coding regions of the $\mathrm{Y}$ chromosome using the phylogenetic tree of $\mathrm{Y}$ chromosome haplogroups, focusing on Japanese groups (Fig. 1). Each primer set was designed using Primer3Plus software (http://primer3plus.com/) to generate amplicons (including each SNP) of $\leq 150$ bp by setting each primer binding site close to SNP. Each primer was checked for the potential self-dimer structures using AutoDimer software (http://www.cstl.nist.gov/biotech/strbase/AutoDimerHomepage/AutoDimerProgramHomepage.htm). We checked each PCR primer set by agarose gel electrophoresis to confirm that each product was peculiar to male DNA and confirmed the allele typing of single base extension products by DNA sequencing with a 3130xl Genetic Analyzer (Applied Biosystems, Foster City, CA, USA).

We ran three mini multiplex PCR systems. System 1 (undecaplex M15, RPS4Y711, M231, P31, P191, M119, IMS-JST021355, M242, P99, M179, and M122) roughly subdivided the Japanese population into haplogroups C, D, D1, D2, D3, O, O1a, O2, O3, N, and Q. System 2 (octaplex IMS-JST022457, M116.1, M125, P151, P120, P42, M179, and P12) further subdivided haplogroup D2, while System 3 (pentaplex SRY465, M95, P31, M88, and PK4) further subdivided haplogroup O2. Each assay was performed using a GeneAmp PCR System 9700 (Applied Biosystems) in 9600 emulation mode with a final volume of $15 \mu 1$. We used a Qiagen Multiplex PCR Plus Kit (Qiagen) and $1 \mathrm{ng}$ of genomic DNA for the assay. Supplementary data 1 shows each primer sequence and its concentration. The cycling programs consisted of pre-denaturation at $95{ }^{\circ} \mathrm{C}$ for $5 \mathrm{~min}$, followed by 35 cycles of denaturation at $95{ }^{\circ} \mathrm{C}$ for $30 \mathrm{~s}$, annealing at $60{ }^{\circ} \mathrm{C}$ for $90 \mathrm{~s}$, extension at $72{ }^{\circ} \mathrm{C}$ for $30 \mathrm{~s}$, and a final extension at $68{ }^{\circ} \mathrm{C}$ for $15 \mathrm{~min}$.

2.3. Multiplex SBE reaction and electrophoresis 
For SNPs analysis, we deployed three mini multiplex systems based on the ABI PRISM SNaPshot ${ }^{\mathrm{TM}}$ Multiplex Kit (Applied Biosystems). Before the multiplex SBE reactions, we cleaned 5- $\mu$ l aliquots of the PCR products by adding $2 \mu \mathrm{l}$ of ExoSAP-IT (USB Products, Affymetrix, Santa Clara, CA, USA) and incubation at $37{ }^{\circ} \mathrm{C}$ for $15 \mathrm{~min}$. The products were subsequently heated at $75{ }^{\circ} \mathrm{C}$ for $15 \mathrm{~min}$ to inactivate the enzyme. We performed each reaction in a $5 \mu \mathrm{l}$ final volume, combining $2.5 \mu \mathrm{l}$ of the SNaPshot Multiplex Ready Reaction Mix, $1 \mu$ of the cleaned PCR product, and each extension primer. The cycling conditions were 25 cycles at $96{ }^{\circ} \mathrm{C}$ for $10 \mathrm{~s}$ each; $50{ }^{\circ} \mathrm{C}$ for $5 \mathrm{~s}$ each; and $60{ }^{\circ} \mathrm{C}$ for $30 \mathrm{~s}$. We attached varying lengths of poly (dGACT) tails at the $5^{\prime}$ end of each extension primer.

Supplementary data 2 shows each primer sequence and its concentration. To remove unincorporated ddNTPs, we incubated the final product with $1 \mathrm{U}$ of shrimp alkaline phosphatase (USB Products, Affymetrix) at $37{ }^{\circ} \mathrm{C}$ for $1 \mathrm{~h}$. The product was subsequently heated at $75^{\circ} \mathrm{C}$ for $15 \mathrm{~min}$ to inactivate the enzyme. We performed electrophoresis with a 3130xl Genetic Analyzer. We then injected samples containing $1 \mu \mathrm{l}$ of the cleaned SBE product, $10 \mu \mathrm{l}$ of Hi-Di formamide (Applied Biosystems), and $0.2 \mu \mathrm{l}$ of the GeneScan-120 LIZ size standard for $2 \mathrm{~s}$ at $2000 \mathrm{~V}$ and separated them at $60{ }^{\circ} \mathrm{C}$ for $16 \mathrm{~min}$. We used GeneMapper ID v3.2.1 software (Applied Biosystems) to perform data analysis.

\subsection{Sensitivity study}

To determine the minimum quantity of DNA required, we used a series of DNA samples (obtained from male subjects) containing $50 \mathrm{pg}, 100 \mathrm{pg}, 200 \mathrm{pg}, 500 \mathrm{pg}, 1 \mathrm{ng}, 2 \mathrm{ng}$, and $5 \mathrm{ng}$ of DNA. The tests were performed five times with different DNA samples.

\subsection{Statistical calculations}

Haplogroup frequencies were determined by direct counting.

\subsection{Analysis of degraded DNA samples}

To assess the effectiveness of our three mini $\mathrm{Y}$ chromosome SNP multiplex systems in genotyping degraded DNA, we used artificially degraded DNA (digested with DNase) and forensic samples characterized by poor DNA quality. We prepared the artificially degraded DNA sample series as described previously [17]. An aliquot of $11.2 \mu \mathrm{g}$ of male genome DNA was mixed with 10× DNase I Reaction Buffer (Invitrogen, Carlsbad, CA, USA) and sterile water to create a total volume of $110 \mu$. From this reaction mixture, we removed $10 \mu \mathrm{l}$ as control DNA undigested by DNase and added $250 \mathrm{mU}$ of DNase I (Invitrogen) to the remaining $100 \mu \mathrm{l}$ volume. We then removed $10 \mu \mathrm{l}$ aliquots from the $100 \mu \mathrm{l}$ mixture at 2, $5,10,30,60,90$, and $120 \mathrm{~min}$. The $10 \mu \mathrm{l}$ aliquots removed were mixed with $2 \mu \mathrm{l}$ of $25 \mathrm{mM}$ EDTA at $75^{\circ} \mathrm{C}$ for $10 \mathrm{~min}$. The samples were mixed with $2 \mu \mathrm{l}$ of $25 \mathrm{mM}$ EDTA at $75^{\circ} \mathrm{C}$ for $10 \mathrm{~min}$. The control DNA was mixed with EDTA in the same manner. From the final volume of $12 \mu \mathrm{l}$, we used $2 \mu \mathrm{l}$ for $10 \%$ polyacrylamide gel electrophoresis to check DNA fragmentation (Fig. 2). The DNA samples were analyzed with the three mini Y chromosome SNP multiplex systems and AmpFLSTR Yfiler Kit (Applied Biosystems). An aliquot ( $2 \mu \mathrm{l})$ of DNA solution from each degraded sample was used in the reaction mixture for PCR. Based on analysis results, we identified 30 samples of degraded DNA for which allele typing was unsuccessful for $>7$ of the 16 loci. We extracted DNA from skeletal remains samples by SDS-proteinase K treatment followed by phenol/chloroform extraction. We performed analyses using the 
three mini Y chromosome SNP multiplex systems and the AmpFLSTR Yfiler Kit as described above to determine whether the systems were suitable for effective analysis of degraded DNA.

\section{Results}

We established three mini Y chromosome SNP multiplex systems using 22 Y chromosome binary markers to identify 23 haplogroups in the Japanese population. Sensitivity studies detected allele peaks at $>150$ relative fluorescence units. In investigating template DNA concentrations with System 1, we observed several additional peaks with $50 \mathrm{pg}$ of template DNA. Interpretation of analyses with $50 \mathrm{pg}$ of template DNA in Systems 2 and 3 proved difficult due to low peaks. To avoid mistyping attributable to extra peaks, we set the low template level between 50 and $100 \mathrm{pg}$. While allele typing was successful in the group with $\geq 5 \mathrm{ng}$ of template DNA, the target peaks were too high, and extra peaks were observed. Thus, we set the maximum template level at $<2 \mathrm{ng}$. Typing proved possible for all samples with template DNA amounts between $100 \mathrm{pg}$ and $2 \mathrm{ng}$, and no significant extra peaks were observed. Within these limits established by DNA detection range analysis, allele typing for all selected SNPs proved successful with each system. Figure 3 shows the results for DNA from 9948 DNA (Promega, Madison, WI) obtained using our systems. When SNP analysis was performed using female DNA as a template or negative control, no PCR bands were detected. Non-expected peaks were occasionally visible, but these peaks did not affect SNP evaluations.

Most of the Japanese population can be classified using these three mini Y chromosome SNP multiplex systems. Table 1 shows the frequency for the Japanese population. Mutations RPS4Y711 (haplogroup C), IMS-JST021355 (haplogroup D), and P191 (haplogroup O), respectively, were 8.3\%, 30.3\%, and 59.0\%, haplogroup frequencies similar to those found in past studies [18-21]. Using Systems 2 and 3, we subdivided populations of haplogroups D2 and O2. In this survey, haplogroup D2a1b (16.2\%) was the most frequent in Japanese haplogroup D populations and haplogroup $\mathrm{O} 2 \mathrm{~b}(32.2 \%)$ the most frequent in the haplogroup O population. The haplogroup frequencies observed in haplogroup D2 and O2 were similar to those reported in previous studies $[19,20]$.

We also investigated the effectiveness of our systems in analyzing degraded samples. We re-analyzed a set of 30 hard tissue samples unsuccessfully examined using the protocol for a commercially available AmpFLSTR Yfiler Kit. This protocol had produced unsatisfactory results for at least 7 of the 16 loci. Figure 4 shows the results of our analysis of the degraded DNA samples. Only 8 alleles were successfully typed using the AmpFLSTR Yfiler Kit; in contrast, the present systems proved able to detect all alleles and define the haplogroup. Table 2 presents the results of our analysis. The present systems proved capable of classifying 29 of 30 degraded DNA samples previously examined unsuccessfully using the AmpFLSTR Yfiler Kit. We also used the three systems to analyze an artificially degraded DNA sample (Table 3). In tests of degraded DNA digested with DNase, typing had failed for more than half the loci. In contrast, the present systems also proved effective with these degraded samples (Supplementary data 3 ).

\section{Discussion}

STR and SNP analyses have become essential tools for determining personal identity based on biological samples. Current research is especially active in the area of autosomal and Y chromosome STRs and SNPs 
[22-27]. We configured three systems to perform simultaneous analysis of biallelic markers on the Y chromosome that classify haplogroups in the Japanese population and began by evaluating the performance of our systems with Japanese haplogroup classification. We applied the newly devised mini Y chromosome SNP multiplex PCR systems to the analysis of samples from 432 Japanese men. The results indicated frequencies of major haplogroups consistent with those found in previous studies [18-21]. For $0.9 \%$ of the Japanese population, we failed to discover any mutations using our three Y chromosome SNP analysis systems. These samples appear to belong to haplogroups I and R [11]. The haplogoup D lineage occurs most frequently in Central Asia and in Japan; the haplogroup D2 lineage is rarely found outside Japan [11]. In this survey, all haplogroup D instances belonged to haplogroup D2, while the frequencies of subhaplogroups D2*, D2a1*, and D2a1b showed no significant differences from previous reports and fine classifications, suggesting that System 2 may be very useful in subdividing the Japanese haplogroup D2 population. Where further classification is required, IMS-JST022456 may help define the subclades of haplogroup D2 [20].

Haplogroup O, the most prevalent haplogroup in Japan, was divided by System 1 and further divided by System 3. In System 1, 21.3\% of samples branched into haplogroup O3. Using System 3, we demonstrated that haplogroup $\mathrm{O} 2$ branched into haplogroup $\mathrm{O} 2 \mathrm{~b}$ (32.2\%). Haplogroups $\mathrm{O} 2 \mathrm{~b}$ and $\mathrm{O} 3$ accounted for more than half the Japanese population. Introducing still another system to subdivide haplogroups $2 \mathrm{~b}$ and $\mathrm{O} 3$ should make it still more useful for personal identification. Reports indicate many individuals in the Japanese haplogroup O2b have the 47z mutation (haplogroup O2b1) [11,25]. Additionally, the Japanese haplogroup $\mathrm{O} 3$ can be divided into further subgroups $[27,28]$.

We found that haplogroup $\mathrm{O}$ accounted for $59.0 \%$ of the samples; haplogroup D for $30.3 \%$ of the samples; and haplogroup C for $8.3 \%$. Several studies indicate haplogroups $\mathrm{C}, \mathrm{D}$, and $\mathrm{O}$ are found in more than $95 \%$ of the East Asian population [18,28], but at differing proportions from country to country. Japan features high proportions of haplogroup D, while South Korea features high proportions of haplogroup C [28]. Genetic differences between East Asians are also evident in mitochondrial DNA haplogroups. Mitochondrial DNA is an excellent tool for forensic genetics due to the high copy numbers per cell and maternal inheritance. Certain mitochondrial haplogroups, such as M7a and N9b, occur frequently in the Japanese population but are rarely encountered in other East Asian populations [29]. Using mitochondrial and Y chromosome SNPs, we can exploit these differences to categorize East Asian populations into the appropriate haplogroups.

Personal identification requires further classification; forensic scientists often encounter major difficulties in analyzing degraded DNA samples.

Quite often, degraded DNA samples cannot be successfully analyzed using commercially available kits subject to sample volume limitations. In forensic examinations, an additional system capable of fine sub-classification may help. The objective of the present study is to apply these methods to analyze degraded samples for forensic purposes. Allele typing by Y chromosome SNPs analysis is easier than with autosomal or X chromosome SNPs because heterozygosities and systems that detect stimulatory $\mathrm{Y}$ chromosome SNP can often predict haplogroups, even with incomplete allele typing. STRs are known to 
produce stutter artifacts differing from true alleles that may complicate analysis; on the other hand, SNP analysis is very simple.

Our new systems containing $22 \mathrm{Y}$ chromosome SNPs promise effective and efficient analysis of highly degraded DNA samples in the Japanese population. The short amplicons used in this study offer the potential to become the tool of choice for analyzing degraded DNA samples [17.30]. To test these hypotheses, we used amplification product lengths between 77 bp (M122) and 150 bp (M231 and M95) for all Y chromosome SNPs. On this basis, our systems proved capable of generating favorable results with highly degraded DNA samples. With samples for which most STRs could not be analyzed with the AmpFLSTR Yfiler Kit, the systems we created were able to type only a few SNPs, suggesting that amplification is inadequate even with $\leq 150 \mathrm{bp}$ amplicons with extensive fragmentation of DNA samples. However, these systems proved effective with samples in which STRs could be detected in >2 loci. Analytical results for artificially degraded samples substituting for highly degraded forensic DNA sources were also superior to those obtained using commercial STR kits. For degraded DNA samples for which alleles were not completely detected, this means these systems can easily determine haplogroups and that even if haplogroups are not determined to precise subgroups, the detected SNPs can help achieve personal identification.

Selecting $22 \mathrm{Y}$ chromosome SNPs and developing Y chromosome SNP multiplex systems (mini Y chromosome SNP) to analyze degraded DNA samples, we demonstrated these systems are capable of identifying polymorphisms in Japanese subjects and of analyzing highly degraded samples for personal identification in forensic studies.

\section{References}

[1] Kinjhodzic R, Kubat M, Skavic J (2004) Bosnian population data for the 15 STR loci in the Power Plex 16 kit. Int J Legal Med 118:119-21.

[2] Veselinovic I, Kubat M, Furac I, Skavic J, Martinovic Klaric I, Tasic M (2004) Allele frequencies of the 15 AmpflSTR Identifiler loci in the population of Vojvodina Province, Serbia and Montenegro. Int J Legal Med 118:184-6.

[3] Kwak KD, Jin HJ, Shin DJ et al (2005) Y-chiromosomal STR haplotypes and their applications to forensic and population studies in east Asia. Int J Legal Med 119:195-201.

[4] Berger B, Lindinger A, Niederstatter H, Grubwieser P, ParsonW (2005) Y-STR typing of an Austrian population sample using a 17-loci multiplex PCR assay. Int J Legal Med 119:241-6.

[5] Thomson R, Pritchard J.K, Shen P, Oefner P.J, Feldman M.W (2000) Recent common ancestry of human Y chromosomames: evidence from DNA sequence data. Proc Natl Acad Sci U S A 97 (13): 7360-5. [6] Sobrino B, Brión M, Carracedo A (2005) SNPs in forensic genetics: a review on SNP typing methodologies. Forensic Sci Int 154:181-194.

[7] Chakraborty R, Stivers DN, Su B, Zhong Y, Budowle B (1999) The utility of short tandem repeat loci beyond human identification : implications for development of new DNA typing systems. Electrophoresis $20: 1682-96$.

[8] Jobling MA, Tyler-Smith C (2003) The human Y chromosome: an evolutionary marker comes of age. 
Nat Rev Genet 4:598-612.

[9] Karafet TM, Mendez FL, Meilerman MB, Underhill PA, Zegura SL, Hammer MF (2008) New binary polymorphisms reshape and increase resolution of the human Y chromosomal haplogroup tree. Genome Res 18:830-8.

[10] International Society Of Genetic Genealogy (http;//www.isogg.org/).

[11] Hammer MF, Karafet TM, Park H, Omoto K, Harihara S, Stoneking M, et al (2006) Dual origins of Japanese: common ground for hunter-gatherer and farmer Y chromosomes. J Hum Genet 51 (1):47-58.

[12] Dixon LA, Dobbins AE, Pulker HK, Butler JM, Vallone PM, Coble MD, et al (2006) Analysis of artificially degraded DNA using STRs and SNPs-results of a collaborative European (EDNAP) exercise. Forensic Sci Int 164:33-44.

[13] Hughes-Stamm SR, Ashton KJ, van Daal A (2011) Assessment of DNA degradation and the genotyping success of highly degraded samples. Int J Legal Med 125:341-8.

[14] Diegoli TM, Coble MD (2011) Development and characterization of two mini-X chromosomal short tandem repeat multiplexes. Forensic Sci Int Genet 5:415-21.

[15] Bai X, Li S, Cong B, Li X, Guo X, He L, et al (2010) Construction of two fluorescencelabeled non-combined DNA index system miniSTR multiplex systems to analyze degraded DNA samples in the Chinese Han Population. Electrophoresis 31:2944-8.

[16] Babol-Pokora K, Berent J (2008) SNP-minisequencing as an excellent tool for analysing degraded DNA recovered from archival tissues. Acta Biochim Pol 55:815-9.

[17] Asamura H, Sakai H, Kobayashi K, Ota M, Fukushima H (2006) MiniX-STR multiplex system population study in Japan and application to degraded DNA analysis. Int J Legal Med 120(3):174-81.

[18] Muro T, Iida R, Fujihara J, Yasuda T, Watanabe Y, Imamura S, et al (2011) Simultaneous determination of seven informative $\mathrm{Y}$ chromosome SNPs to differentiate East Asian, European, and African populations. Leg Med (Tokyo) 13:134-41.

[19] Nonaka I, Minaguchi K, Takezaki N (2007) Y-chromosomal binary haplogroups in the Japanese population and their relationship to 16 Y-STR polymorphisms. Ann Hum Genet. ;71:480-95.

[20] Naitoh S, Kasahara-Nonaka I, Minaguchi K, Nambiar P.(2013) Assignment of Y-chromosomal SNPs found in Japanese population to Y-chromosomal haplogroup tree. J Hum Genet. 58(4):195-201.

[21] Mizuno N, Kitayama T, Fujii K, Nakahara H, Yoshida K, Sekiguchi K, et al (2010) A forensic method for the simultaneous analysis of biallelic markers identifying $\mathrm{Y}$ chromosome haplogroups inferred as having originated in Asia and the Japanese archipelago. Forensic Sci Int Genet. 4(2):73-9.

[22] Sanchez JJ, Phillips C, Børsting C, Balogh K, Bogus M, Fondevila M, et al (2006) A multiplex assay with 52 single nucleotide polymorphisms for human identification. Electrophoresis 27:1713-24.

[23] Lee HY, Park MJ, Yoo JE, Chung U, Han GR, Shin KJ (2005) Selection of twenty-four highly informative SNP markers for human identification and paternity analysis in Koreans. Forensic Sci Int 148:107-12.

[24] Sanchez JJ, Børsting C, Hallenberg C, Buchard A, Hernandez A, Morling N (2003) Multiplex PCR and minisequencing of SNPs-a model with 35 Y chromosome SNPs. Int J Legal Med 137:74-84. 
[25] Völgyi A, Zalán A, Szvetnik E, Pamjav H (2009).Hungarian population data for 11 Y-STR and 49 Y-SNP markers. Forensic Sci Int Genet 3:e27-8.

[26] Brion M, Sobrino B, Blanco-Verea A, Lareu MV, Carracedo A (2005) Hierarchical analysis of 30 Y-chromosome SNPs in European populations. Int J Legal Med 119:10-5.

[27] Caratti S, Gino S, Torre C, Robino C (2009) Subtyping of Y-chromosomal haplogroup E-M78 (E1b1b1a) by SNP assay and its forensic application. Int J Legal Med 123:357-60.[28] Park MJ, Lee HY, Kim NY, Lee EY, Yang WI, Shin KJ (2013) Y-SNP miniplexes for East Asian Y-chromosomal haplogroup determination in degraded DNA. Forensic Sci Int Genet 7:75-81.

[29] Umetsu K, Tanaka M, Yuasa I, Adachi N, Miyoshi A, Kashimura S, et al (2005) Multiplex amplified product-length polymorphism analysis of 36 mitochondrial single-nucleotide polymorphisms for haplogrouping of East Asian populations. Electrophoresis.26(1):91-8.

[30] Asamura H, Fujimori S, Ota M, Oki T, Fukushima H (2008) Evaluation of miniY-STR multiplex PCR systems for extended 16 Y-STR loci. Int J Legal Med 122(1):43-9.

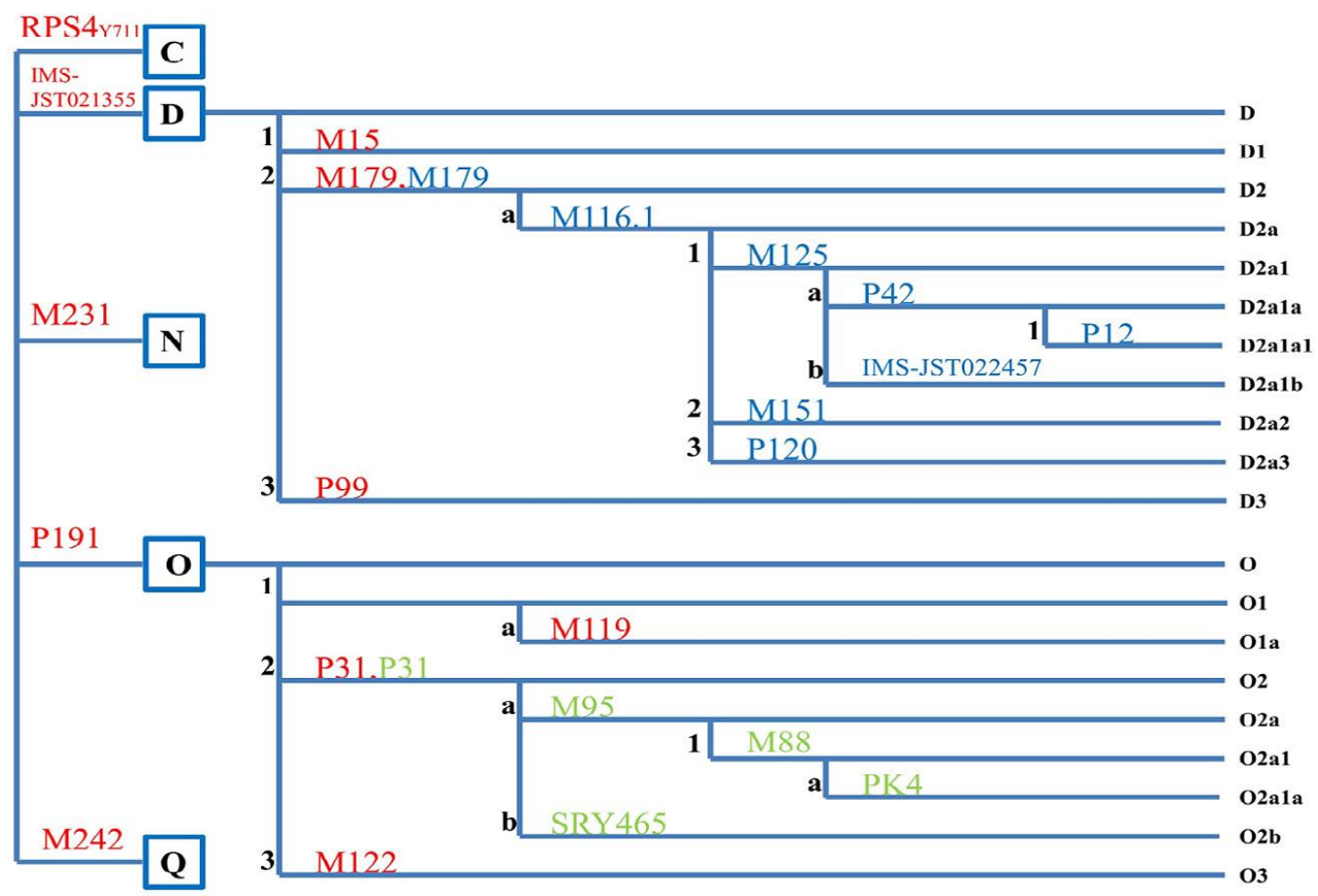

Fig. 1

Phylogenetic tree of $22 \mathrm{Y}$ chromosome binary polymorphisms analyzed in this study. Marker names are indicated above the lines. SNPs are indicated by red letters in System 1, blue letters in System 2, and green letters in System 3. 


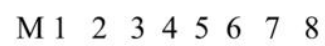

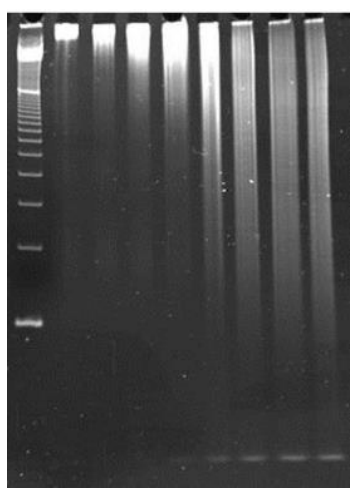

Fig. 2

Gel electrophoresis of degraded DNA series by Dnase I digestion. M, 100 bp marker, lane 1, control (no digestion with Dnase I); 2, digestion with Dnase I for $2 \mathrm{~min} ; 3$, $5 \mathrm{~min} ;$ 4, $10 \mathrm{~min} ; 5,30 \mathrm{~min}$; 6, $60 \mathrm{~min}$; , $90 \mathrm{~min} ; 8,120 \mathrm{~min}$.

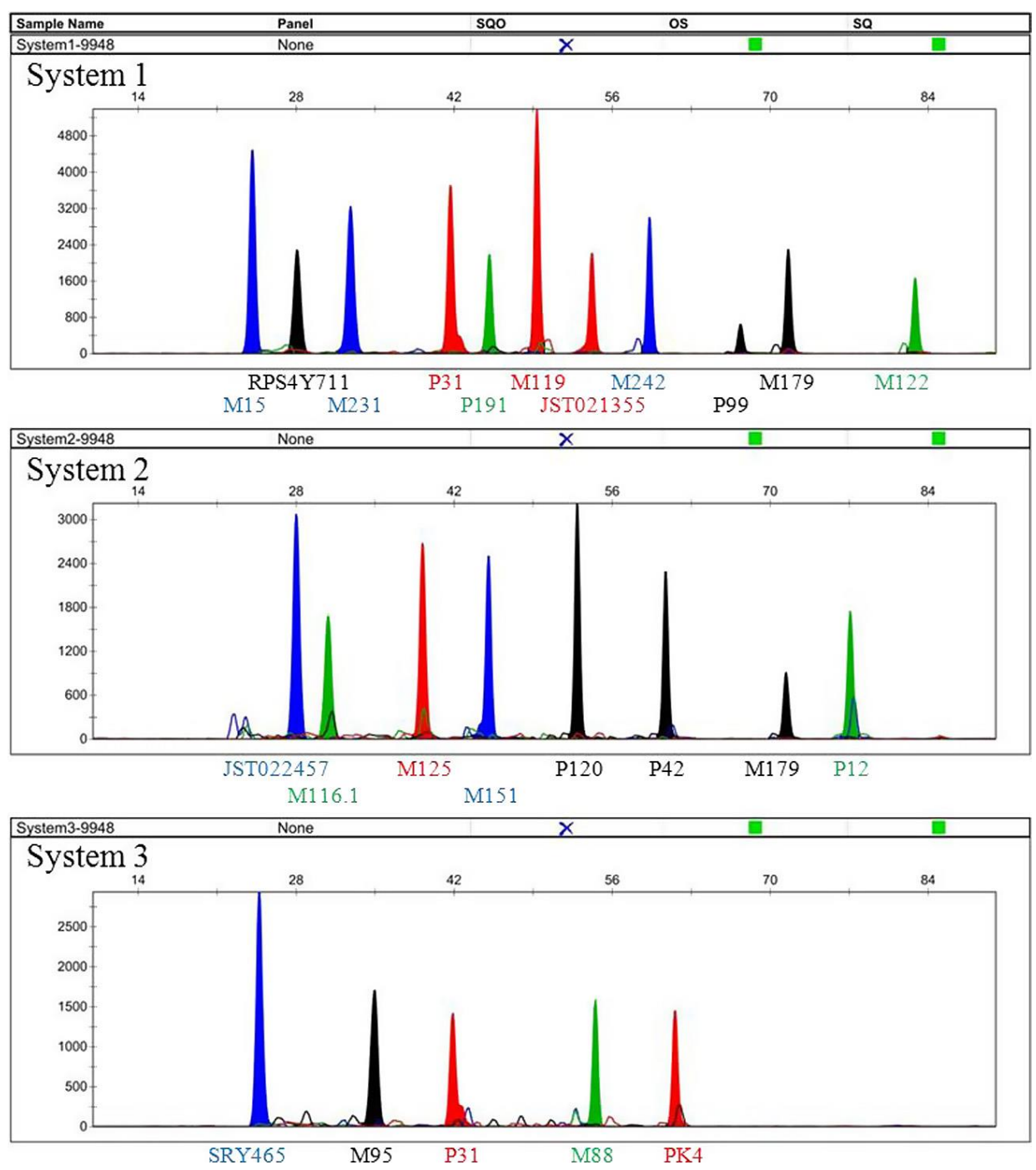

Fig. 3

Electropherograms for 9948 DNA obtained using the present SNP systems. 

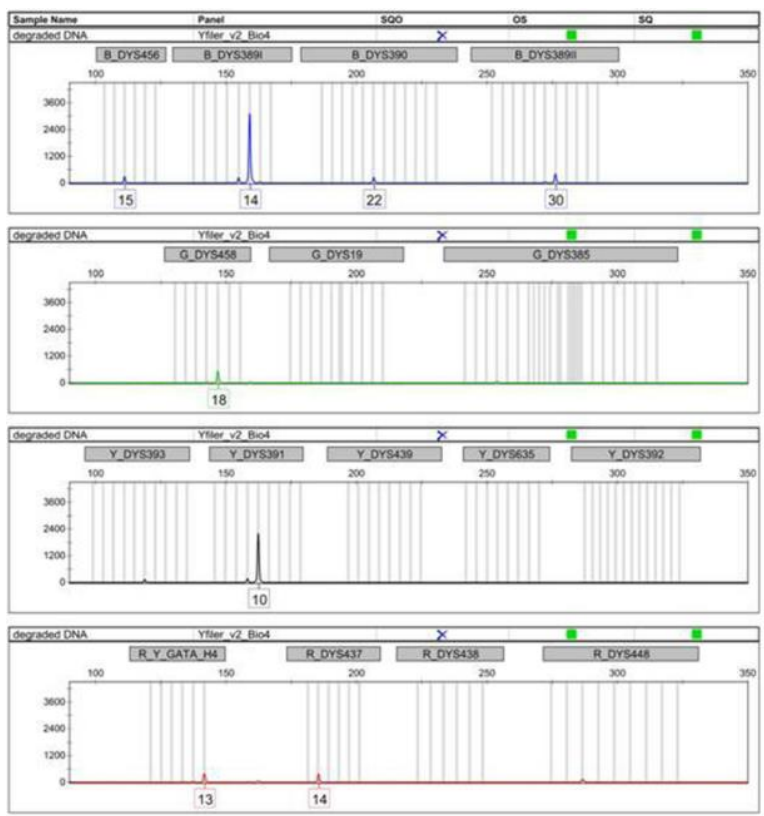

(a)
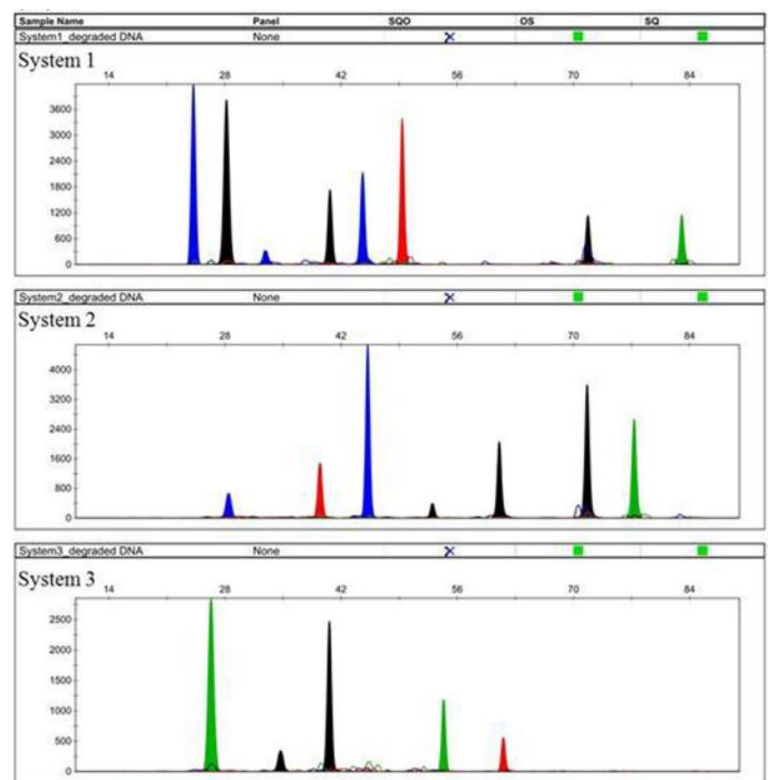

(b)

Fig. 4

(a) Electropherograms for degraded DNA sample from a male, extracted from a hard tissue sample and obtained using the AmpFLSTR Yfiler Kit (Applied Biosystems). (b) Electropherograms for degraded DNA samples from a male, extracted from hard tissue sample and obtained using the present SNP systems.

Table 1 The haplogroup freqencies for Japansese population

\begin{tabular}{lll}
\hline Haplogroup & No. of samples & Frequency \\
\hline $\mathrm{C}$ & 36 & 0.083 \\
$\mathrm{D} *$ & 0 & 0 \\
$\mathrm{D} 1$ & 0 & 0 \\
$\mathrm{D} 2 *$ & 22 & 0.051 \\
$\mathrm{D} 2 \mathrm{a}^{*}$ & 29 & 0.067 \\
$\mathrm{D} 2 \mathrm{a} 1^{*}$ & 3 & 0.007 \\
$\mathrm{D} 2 \mathrm{a} 1 \mathrm{a} *$ & 6 & 0.014 \\
$\mathrm{D} 2 \mathrm{a} 1 \mathrm{a} 1$ & 0 & 0 \\
$\mathrm{D} 2 \mathrm{a} 1 \mathrm{~b}$ & 70 & 0.162 \\
$\mathrm{D} 2 \mathrm{a} 2$ & 0 & 0 \\
$\mathrm{D} 2 \mathrm{a} 3$ & 1 & 0.002 \\
$\mathrm{D} 3$ & 0 & 0 \\
$\mathrm{~N}$ & 4 & 0.009 \\
$\mathrm{O} *$ & 0 & 0 \\
O1* & 0 & 0 \\
O1a & 7 & 0.016 \\
O2* & 15 & 0.035 \\
O2a* & 0 & 0 \\
O2a $*$ & 0 & 0 \\
O2a $1 \mathrm{a}$ & 0 & 0 \\
O2b & 139 & 0.322 \\
O3 & 94 & 0.218 \\
Q & 2 & 0.005 \\
Not determined & 4 & 0.009 \\
\hline
\end{tabular}


Table 2 The result of allele typing using the Y-SNPs multiplex systems for degraded DNA

\begin{tabular}{|c|c|c|c|c|c|}
\hline Sample No & $\begin{array}{l}\text { AmpflSTR } \\
\text { Yfiler Kit }\end{array}$ & System 1 & System 2 & System 3 & Haplogroup \\
\hline 1 & $9^{\mathrm{a}}$ & $9^{\mathrm{b}}$ & 3 & 3 & $(-)^{c}$ \\
\hline 2 & 7 & 9 & 8 & 5 & $\mathrm{O} 2 \mathrm{~b}$ \\
\hline 3 & 3 & 11 & 6 & 5 & $\mathrm{O} 2 \mathrm{~b}$ \\
\hline 4 & 8 & 10 & 6 & 5 & $\mathrm{O} 2 \mathrm{~b}$ \\
\hline 5 & 9 & 10 & 6 & 5 & $\mathrm{D} 2 \mathrm{a} 1 *$ \\
\hline 6 & 9 & 11 & 7 & 5 & D2a1a* \\
\hline 7 & 9 & 10 & 8 & 5 & D2alb \\
\hline 8 & 9 & 10 & 8 & 5 & $\mathrm{O} 2 \mathrm{~b}$ \\
\hline 9 & 8 & 8 & 7 & 5 & $\mathrm{O} 2 \mathrm{~b}$ \\
\hline 10 & 9 & 8 & 7 & 5 & D2alb \\
\hline 11 & 9 & 8 & 7 & 4 & D2alb \\
\hline 12 & 9 & 8 & 8 & 5 & D2ala* \\
\hline 13 & 9 & 10 & 6 & 4 & Q \\
\hline 14 & 6 & 7 & 7 & 5 & $\mathrm{O} 2 \mathrm{~b}$ \\
\hline 15 & 6 & 5 & 5 & 5 & $\mathrm{O} 2 \mathrm{~b}$ \\
\hline 16 & 7 & 8 & 5 & 4 & $\mathrm{O} 3$ \\
\hline 17 & 3 & 9 & 6 & 4 & D2ala* \\
\hline 18 & 6 & 11 & 8 & 5 & $\mathrm{O} 3$ \\
\hline 19 & 2 & 8 & 7 & 2 & Ola \\
\hline 20 & 9 & 11 & 7 & 4 & $\mathrm{O} 3$ \\
\hline 21 & 8 & 7 & 8 & 5 & D2alb \\
\hline 22 & 4 & 8 & 8 & 5 & $\mathrm{D} 2 *$ \\
\hline 23 & 7 & 10 & 8 & 5 & D2a* \\
\hline 24 & 7 & 10 & 8 & 5 & $\mathrm{O} 2 \mathrm{~b}$ \\
\hline 25 & 9 & 9 & 8 & 5 & $\mathrm{O} 2 *$ \\
\hline 26 & 9 & 9 & 6 & 4 & $\mathrm{O} 3$ \\
\hline 27 & 6 & 8 & 7 & 5 & $\mathrm{O} 2 \mathrm{~b}$ \\
\hline 28 & 8 & 8 & 8 & 5 & D2a* \\
\hline 29 & 6 & 9 & 7 & 5 & D2alb \\
\hline 30 & 9 & 7 & 8 & 5 & D2a* \\
\hline
\end{tabular}

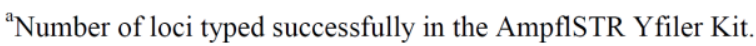

${ }^{b}$ Number of loci typed successfully in miniY-SNP systems.

${ }^{\mathrm{c}}(-)$ indicate not fully infomation.

Table 3 The result of allele typing using the Y-SNPs multiplex systems for artifically degraded DNA

\begin{tabular}{ccccc}
\hline $\begin{array}{l}\text { Enzyme reaction } \\
\text { time (min) }\end{array}$ & $\begin{array}{c}\text { AmpflSTR } \\
\text { Yfiler Kit }\end{array}$ & System 1 & System 2 & System 3 \\
\hline 0 & $16^{\mathrm{a}}$ & $11^{\mathrm{b}}$ & 8 & 5 \\
2 & 16 & 11 & 8 & 5 \\
5 & 16 & 11 & 8 & 5 \\
10 & 16 & 11 & 8 & 5 \\
30 & 16 & 11 & 8 & 5 \\
60 & 11 & 11 & 8 & 5 \\
90 & 7 & 11 & 8 & 5 \\
120 & 6 & 11 & 8 & 5 \\
\hline
\end{tabular}

${ }^{\mathrm{a}}$ Number of loci typed successfully in the AmpflSTR Y filer Kit.

${ }^{\mathrm{b}}$ Number of loci typed successfully in miniY-SNP systems. 
Supplementary data 1 Primer sequences used in this study.

\begin{tabular}{|c|c|c|c|c|c|}
\hline \multirow[t]{2}{*}{ Locus } & \multirow{2}{*}{$\begin{array}{l}\text { dbSNPs } \\
\text { accesion }\end{array}$} & \multicolumn{2}{|c|}{ PCR primers } & \multirow{2}{*}{$\begin{array}{c}\text { Primer } \\
\text { concentration }(\mu \mathrm{M})\end{array}$} & \multirow{2}{*}{$\begin{array}{l}\text { Amplicon } \\
\text { size (bp) }\end{array}$} \\
\hline & & Forward primer & Reverse primer & & \\
\hline \multicolumn{6}{|c|}{ System 1} \\
\hline M15 & rs3906 & GGTCTGCTAACCCACTGCAC & CCTCATGCGCATATACAATCA & 0.053 & 97 \\
\hline M231 & rs9341278 & GGAAAATGTGGGCTCGTT & GACACCACAGAAATTACAGGTATGA & 0.047 & 150 \\
\hline P31 & & CAGTAGGATTTTGGGGAACA & GTGTGAGACTCCATCGCAAA & 0.053 & 100 \\
\hline P191 & rs16980601 & CGACTTCTCAATTCTCGCAAA & TGGTAGGAGCCAAGAGTGGT & 0.133 & 97 \\
\hline M242 & rs 8179021 & AAAAAGGTGACCAAGGTGCT & TTTCGCTTTAAGGGCTTTCA & 0.053 & 149 \\
\hline P99 & & GCAGAGCTTGCAGTGAGTTG & TTTCACAAAGGAGGGGAGAA & 0.060 & 149 \\
\hline M179 & rs2032596 & GCTCAGTTGCCTGAAGATGAA & CAAACCAACGCACTTTTGG & 0.033 & 101 \\
\hline M122 & & CTTTGAGAGTCACTTGCTCTGTG & AGTTGCCTTTTGGAAATGAA & 0.067 & 77 \\
\hline \multicolumn{6}{|c|}{ System 2} \\
\hline IMS-JST022457 & $\mathrm{rs} 2268591$ & CCAATGACACAGGGAAAACA & TGTTTGTGTGAGGTGGATTGA & 0.060 & 127 \\
\hline P42 & & AAAGAGGGGGAGAGACTGAGA & CCTGATGAGGGCATTTCTCT & 0.067 & 120 \\
\hline M179 & rs2032596 & GCTCAGTTGCCTGAAGATGAA & CAAACCAACGCACTTTTGG & 0.033 & 101 \\
\hline P12 & & GGACCATCACCTGGGTAAAGT & CATGATGGACCGAGATACGA & 0.040 & 82 \\
\hline \multicolumn{6}{|c|}{ System 3} \\
\hline SRY465 & rs11575897 & TCTTGAGTGTGTGGCTTTCG & CCGAAGAATTGCAGTTTGCT & 0.047 & 111 \\
\hline M95 & rs 2032650 & CCTTCTTGGGATCAAATGGA & TGGTAGTGCACCTGTTTTGTG & 0.067 & 150 \\
\hline P31 & & CAGTAGGATTTTGGGGAACA & GTGTGAGACTCCATCGCAAA & 0.067 & 100 \\
\hline M88 & rs 2032645 & GGCTATGGCCTAGGTGCTTT & TGTGACCACAGAGACTCAGGA & 0.133 & 148 \\
\hline$\underline{\mathrm{PK} 4}$ & & AATCGGCAATGGTTTTTGAG & AAAGACAGGAGCAGCAGAGG & 0.040 & 140 \\
\hline
\end{tabular}

Supplementary data $2 \mathrm{SBE}$ primer sequences.

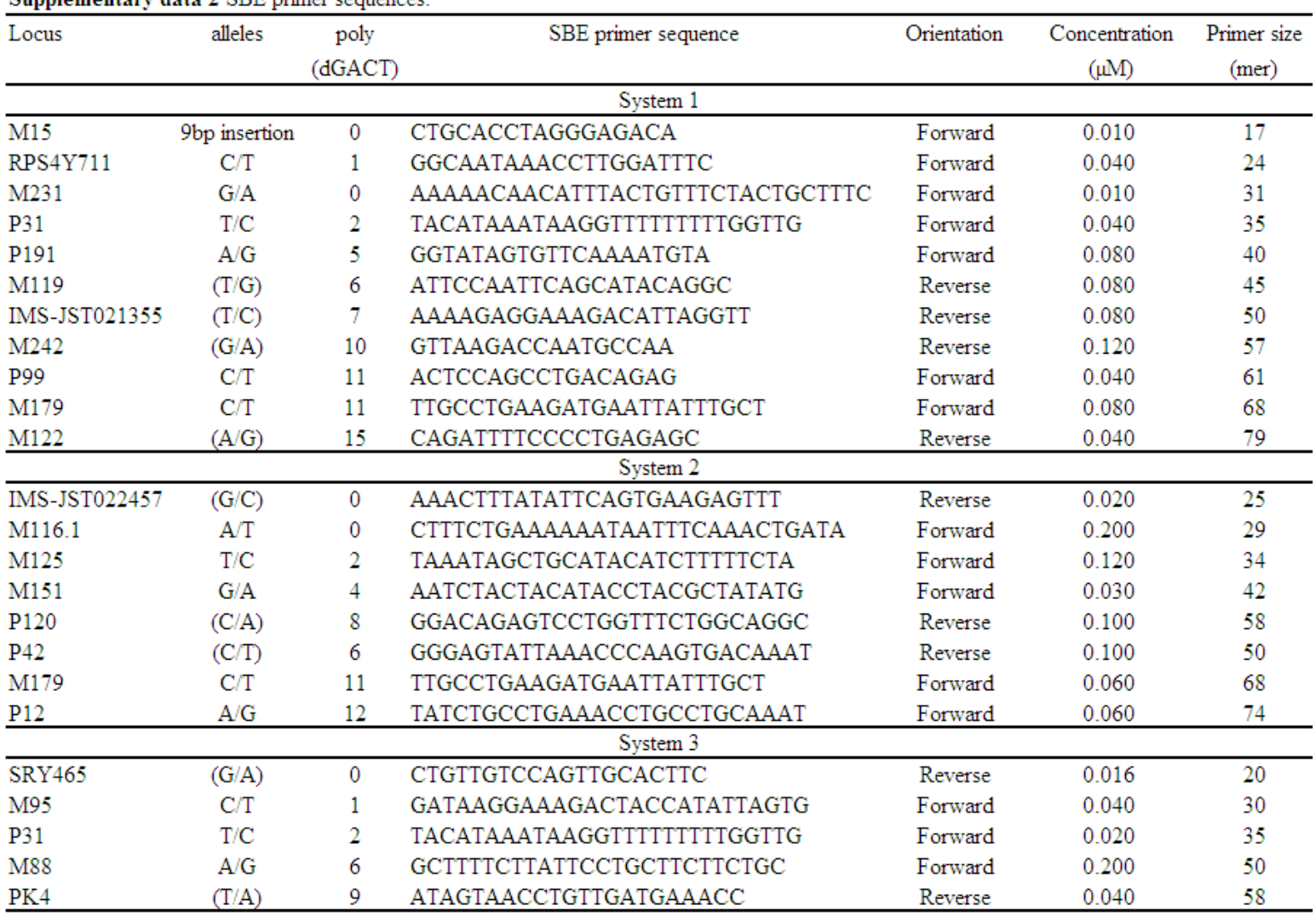


(a)
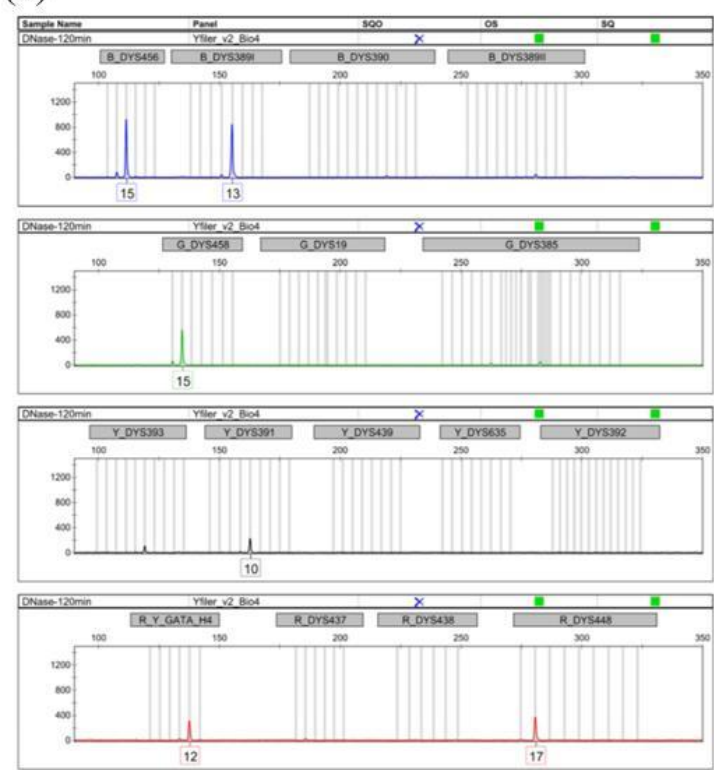

(b)

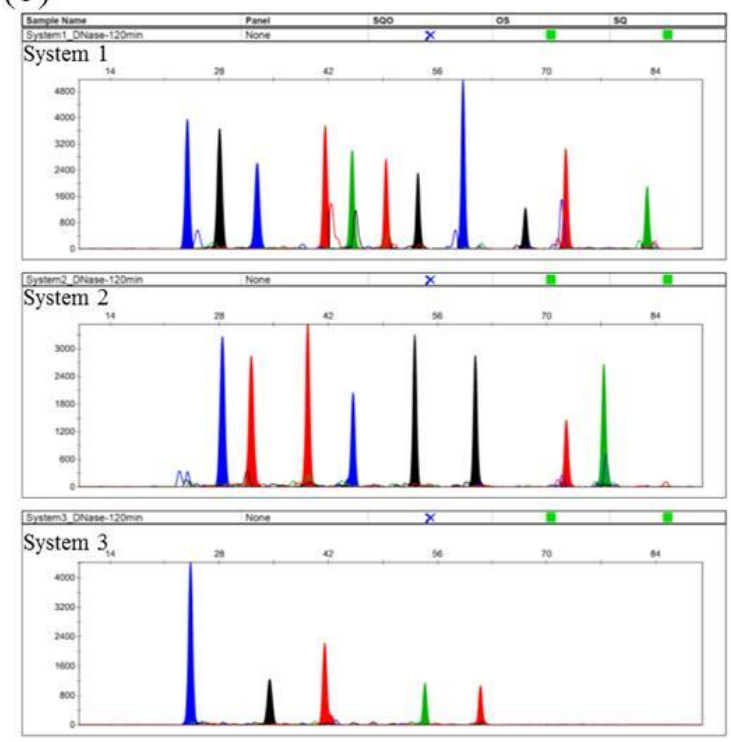

Supplementary data 3

(a) Electropherograms for degraded DNA sample from a Japanese individual, digested with DNase I for 120 min, and obtained using the AmpFLSTR Yfiler Kit (Applied Biosystems). (b) Electropherograms for the degraded DNA sample of a Japanese, which was digested with DNase I for 120 min, obtained using the present SNP systems. 